\title{
Open access in silico tools to predict the ADMET profiling and PASS (Prediction of Activity Spectra for Substances of Bioactive compounds of Garlic (Allium sativum L.)
}

\author{
Ivan Vito Ferrari, ${ }^{1}$
}

1. Department of Industrial Engineering and LIME Laboratory, University of Rome Tor Vergata,

Via del Politecnico 1, 00133 Rome, Italy; Ivan.Vito.Ferrari@uniroma2.it (I.V.F.)

*Corresponding Author: Ivan.Vito.Ferrari@uniroma2.it

Graphical abstract

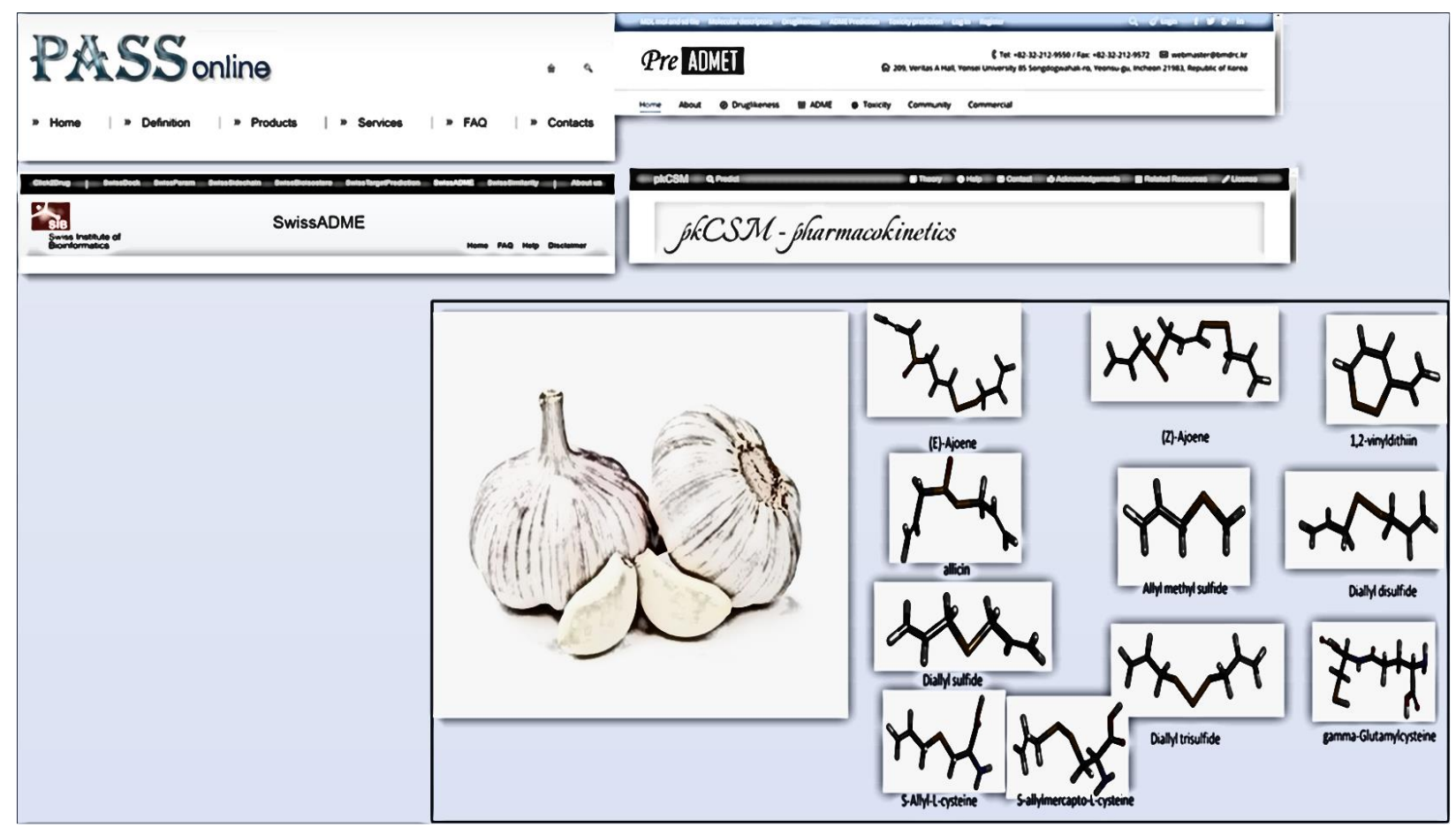

Keywords: in silico; ADMET; drug; open access; prediction; PASS Online ( (Prediction of Activity Spectra for Substances), Garlic Compounds; S-allylcysteine ( SAC) and S-allylmercaptocysteine (SAMC)

Abstract

Background: Garlic (Allium sativum L.) is a common spice with many health benefits, mainly due to its diverse bioactive compounds, (see below) such as organic sulphides, saponins, phenolic compounds, and polysaccharides. Several studies have demonstrated its functions such as antiinflammatory, antibacterial, and antiviral, antioxidant, cardiovascular protective and anticancer 
property. In this work we have investigated the main bioactive components of garlic through a bioinformatics approach. Indeed, we are in an era of bioinformatics where we can predict data in the fields of medicine. Approaches with open access in silico tools have revolutionized disease management due to early prediction of the absorption, distribution, metabolism, excretion, and toxicity (ADMET) profiles of the chemically designed and eco-friendly next-generation drugs. Methods: This paper encompasses the fundamental functions of open access in silico prediction tools, as PASS database (Prediction of Activity Spectra for Substances) that it estimates the probable biological activity profiles for compounds. This paper also aims to help support new researchers in the field of drug design and to investigate best bioactive compounds in garlic. Results: screening through each of pharmacokinetic criteria resulted in identification of Garlic compounds that adhere to all the ADMET properties. Conclusions: It was established an open-access database (PASS database, available bioinformatics tool SwissADME, PreADMET pkCSM database) servers were employed to determine the ADMET (metabolism, distribution, excretion, absorption, and toxicity) attributes of garlic molecules and to enable identification of promising molecules that follow ADMET properties.

\section{Introduction}

Garlic (Allium sativum L.) is a species in the onion genus Allium. This is a common spice with many health benefits, mainly due to its diverse bioactive compounds, (see below fig.1) such as organic sulphides, saponins, phenolic compounds, and polysaccharides. Garlic has been demonstrated to exhibit potentially beneficial for cancer prevention. Several studies have demonstrated its functions such as anti-inflammatory, antibacterial, and antiviral, antioxidant, cardiovascular protective. anticancer property. [1-2] Observations over the past years have shown that the consumption of garlic in the diet provides strong protection against cancer risk. [2]. In literature we can find some papers, where it was demonstrated decreased rates stomach cancer associated with garlic intake. [3-5]

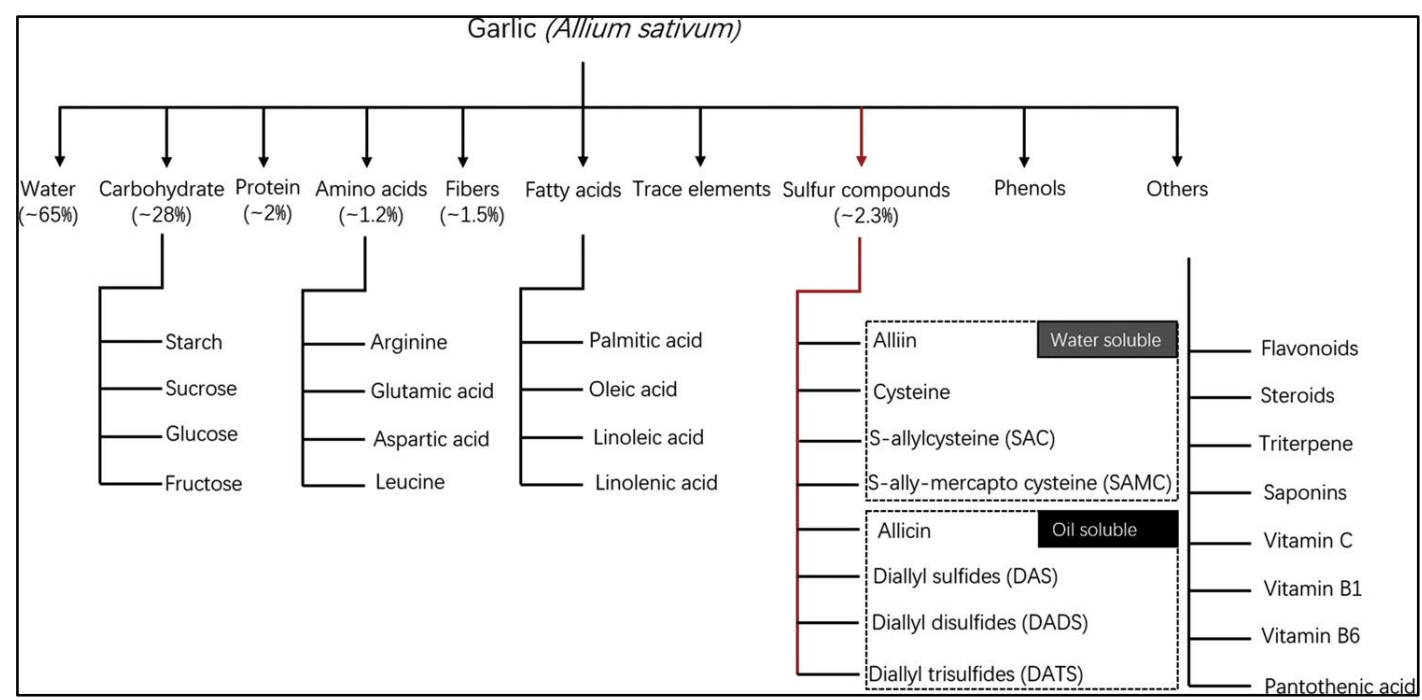

Fig. 1. Major classification of the bioactive constituents in garlic. Generally, garlic bulb contains approximately $65 \%$ water, $28 \%$ carbohydrates (mainly fructans), $2 \%$ protein (mainly alliin), 1.2 \% free amino acids (mainly arginine), $1.5 \%$ fiber, and 2.3 
In this work we have investigated the main bioactive components of garlic through a bioinformatics approach. Indeed, we are in an era of bioinformatics where we can predict data in the fields of medicine. Approaches with open access in silico tools have revolutionized disease management due to early prediction of the absorption, distribution, metabolism, excretion, and toxicity (ADMET) profiles of the chemically designed and eco-friendly next-generation drugs. [6-7] This paper encompasses the fundamental functions of open access in silico prediction tools, as PASS database (Prediction of Activity Spectra for Substances) that it estimates the probable biological activity profiles for compounds. [8-9] This paper also aims to help support the researchers in the field of drug design and to investigate best bioactive compounds in garlic. As it has been before, Garlic contains $0.1-0.36 \%$ of a volatile oil these volatile compounds are generally considered to be responsible for most of the pharmacological properties of garlic. Garlic contains at least 33 sulfur compounds like aliin, allicin, ajoene, allylpropl, diallyl, trisulfide, s-allylcysteine, vinyldithiines, Sallylmercaptocystein, and others. Particular attention has been given to sulphide compounds of garlic for their anti-tumour properties, S-allylcysteine ( SAC) and S-allylmercaptocysteine (SAMC) ( See below fig.1-2) [10-20] It was established an open-access database (PASS database, available bioinformatics tool SwissADME, PreADMET pkCSM database) servers were employed to determine the ADMET (metabolism, distribution, excretion, absorption, and toxicity) attributes of garlic molecules and to enable identification of promising molecules that follow ADMET properties. [6-9]

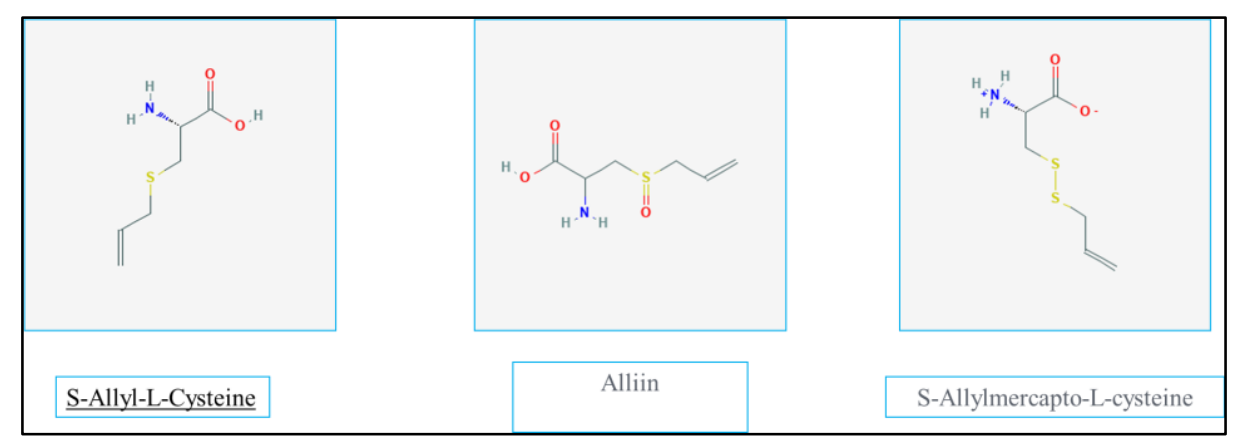

Fig 2 bioactive constituents in garlic sulphur compounds

\section{Materials and methods}

This paper encompasses the fundamental functions of open access in silico prediction tools, as PASS database, PreADMET and pkCSM (http://biosig.unimelb.edu.au/pkcsm/) servers were employed to determine the ADMET (metabolism, distribution, excretion, absorption, and toxicity) attributes of target molecules. PASS (Prediction of Activity Spectra for Substances) Online predicts over 4000 kinds of biological activity, including pharmacological effects, mechanisms of action, toxic and adverse effects, interaction with metabolic enzymes and transporters, influence on gene expression, etc. The first strategy is based on the suggestion that the more kinds of activity are predicted as probable for a compound, the more probable to find any useful pharmacological action in it. Prediction is based on the analysis of structure activity-relationships for more than 250,000 biologically active substances including drugs and drug-candidates. [8] The available bioinformatics tool SwissADME (http://www.swissadme.ch/index.php) [7] was used for finding drug-likeness attributes. Lipinski's rule of five [6] was used to analyze the properties such as; hydrogen bond donor (HBD), hydrogen bond acceptor (HBA), molecular weight (MW), and lipophilicity (log P). 
PreADMET (https://preadmet.bmdrc.kr/) and pkCSM (http://biosig.unimelb.edu.au/pkcsm/) servers were employed to determine the ADMET (metabolism, distribution, excretion, absorption, and toxicity) attributes of target molecules.

\subsection{Classification of the bioactive constituents in garlic}

3D Conformer of several bioactive constituents in garlic were download from PubChem (https://pubchem.ncbi.nlm.nih.gov/) and create by Discovery Studio Biovia Visualizer Software [21] ( see fig.3)

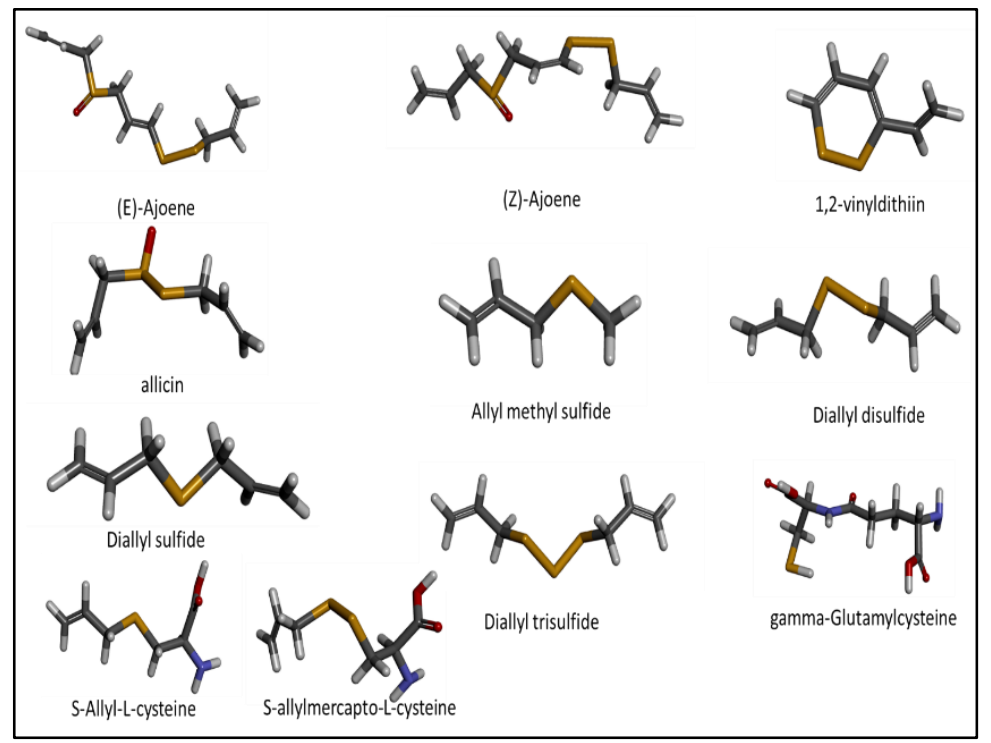

Fig 3 Principal Organosulfur Compounds From Garlic. Reproduced by Discovery Studio Biovia Visualizer Software [21]

\section{Results and discussion}

\subsection{PASS database (Prediction of Activity Spectra for Substances)}

PASS Online predicts over 3500 kinds of biological activity, including pharmacological effects, mechanisms of action, toxic and adverse effects, interaction with metabolic enzymes and transporters, influence on gene expression, etc. Prediction is based on the analysis of structure activityrelationships for more than 250,000 biologically active substances including drugs, drug-candidates, leads and toxic compounds. The concept of the biological activity spectrum was introduced to describe the properties of biologically active substances. The PASS (prediction of activity spectra for substances) software product, which predicts more than 300 pharmacological effects and biochemical mechanisms on the basis of the structural formula of a substance, may be efficiently used to find new targets (mechanisms) for some ligands and, conversely, to reveal new ligands for some biological targets. Average accuracy of prediction estimated in leave-one-out cross-validation procedure (each compound is excluded from the training set and its activity predicted based on SAR model obtained on the rest part of the training set) for the whole PASS training set is about 95\% (Filimonov and Poroikov, 2008) [22]. Since PASS service is used by medicinal chemists, pharmacologists and toxicologists for several years (Lagunin et al., 2000) [23], there are many publications where PASS predictions were confirmed by subsequent synthesis and biological testing. To provide more accurate predictions for compounds belonging to new chemical classes and to extend the predictable area onto 
new biological activities, we are permanently working on enlargement of PASS training set. Input data represents a structural formula of a compound in MOL file format. The output file represents a list of activities with two probabilities $\mathrm{Pa}$ (probability to be active) and Pi (probability to be inactive). $\mathrm{Pa}$ (probability "to be active") estimates the chance that the studied compound is belonging to the sub-class of active compounds (resembles the structures of molecules, which are the most typical in a sub-set of "actives" in PASS training set). Pi (probability "to be inactive") estimates the chance that the studied compound is belonging to the sub-class of inactive compounds (resembles the structures of molecules, which are the most typical in a sub-set of "inactives" in PASS training set). The first strategy is based on the suggestion that the more kinds of activity are predicted as probable for a compound, the more probable to find any useful pharmacological action in it. For each compound from available set of samples the following value can be calculated: [8-9] ; [22-23]

$$
\mathrm{P}=\frac{1}{n} \sum \frac{P_{a}}{P_{a}+P_{i}}
$$

Fig 4 Prediction of Activity Spectra for Substances calculated : the output file represents a list of activities with two probabilities Pa (probability to be active) and Pi (probability to be inactive ${ }^{[8-9] ;[22-23]}$

In Tab 1 we report chemical-physical properties of Principal Organosulfur Compounds , Sallylcysteine ( SAC) and S-allylmercaptocysteine (SAMC) in Garlic investigated by Pass Online Server ( Prediction of Activity Spectra for Substances ) that it estimates the probable biological activity profiles for compounds. As we can see from the table 1, SAMC and SAC demonstrated to a suppressive agent against several tumours and they have several functions such as antiinflammatory, antibacterial, and antiviral, antioxidant, cardiovascular protective. [10-20] Sallylcysteine ( SAC) and S-allylmercaptocysteine (SAMC) have a high value of 0.96-0.98 Pa (probability to be active) in human flavin-containing monooxygenase 3 (FMO3) and it has impact on enzyme activity, drug metabolism and disease. [28-29] Indeed, A flavin-containing monooxygenase (FMO) produced by A. sativum (AsFMO) was previously proposed to oxidize $S$ allyl-L-cysteine (SAC) to alliin, an allicin precursor. 30. Ferreira F, et all., (2013) have investigated the activity of the human flavin-containing monooxygenase (FMO) has been proposed to be impact on enzyme activity, drug metabolism and disease, like Trimethylaminuria (TMAu) or "fish odor syndrome" is a metabolic disorder characterized by the inability to convert malodorous dietarily-derived trimethylamine (TMA) to odourless TMA N-oxide by the flavin-containing monooxygenase 3 (FMO3). [30] 


\begin{tabular}{|c|c|c|c|c|c|}
\hline \multirow[t]{10}{*}{ S-Allyl-L-cysteine } & $\mathrm{C}_{6} \mathrm{H}_{11} \mathrm{NO}_{2} \mathrm{~S}$ & 161.22 & $\mathrm{~Pa}$ & $\mathrm{Pi}$ & Acitivity \\
\hline & & & 0,965 & 0,002 & Flavin-containing monooxygenase substrate \\
\hline & & & 0,963 & 0,003 & CYP2E1 substrate \\
\hline & & & 0,962 & 0,003 & CYP2E substrate \\
\hline & & & 0,942 & 0,001 & S-alkylcysteine lyase inhibitor \\
\hline & & & 0,939 & 0,002 & NADPH peroxidase inhibitor \\
\hline & & & 0,933 & 0,002 & FMO3 substrate \\
\hline & & & 0,928 & 0,002 & Lysine 2,3-aminomutase inhibitor \\
\hline & & & 0,924 & 0,003 & Acylcarnitine hydrolase inhibitor \\
\hline & & & 0,905 & 0,004 & Arylacetonitrilase inhibitor \\
\hline \multirow[t]{15}{*}{ S-allylmercapto-L-cysteine } & $\mathrm{C}_{6} \mathrm{H}_{11} \mathrm{NO}_{2} \mathrm{~S}_{2}$ & 193.3 & $\mathrm{~Pa}$ & $\mathrm{Pi}$ & Acitivity \\
\hline & & & 0,974 & 0,002 & Flavin-containing monooxygenase substrate \\
\hline & & & 0,967 & 0,001 & FMO3 substrate \\
\hline & & & 0,939 & 0,002 & NADPH peroxidase inhibitor \\
\hline & & & 0,939 & 0,002 & Protein-disulfide reductase (glutathione) inhibitor \\
\hline & & & 0,934 & 0,003 & CYP2E1 substrate \\
\hline & & & 0,933 & 0,003 & CYP2E substrate \\
\hline & & & 0,932 & 0,003 & Antiseborrheic \\
\hline & & & 0,928 & 0,003 & Lipid metabolism regulator \\
\hline & & & 0,925 & 0,004 & Apoptosis agonist \\
\hline & & & 0,924 & 0,003 & Acylcarnitine hydrolase inhibitor \\
\hline & & & 0,919 & 0,001 & Cysteamine dioxygenase inhibitor \\
\hline & & & 0,916 & 0,003 & Arylacetonitrilase inhibitor \\
\hline & & & 0,909 & 0,002 & S-alkylcysteine lyase inhibitor \\
\hline & & & 0,903 & 0,005 & TP53 expression enhancer \\
\hline
\end{tabular}

Tab 1 Prediction of Activity Spectra for Substances of Principal Organosulfur Compounds, as S-allylcysteine (SAC) and S-allylmercaptocysteine (SAMC)

\subsection{In silico Organosulfur Compounds analysis and ADMET profiling}

The available bioinformatics tool SwissADME (http://www.swissadme.ch/index.php) [7,24] was used for finding drug-likeness attributes. Lipinski's rule of five [6] was used to analyze the properties such as; hydrogen bond donor (HBD), hydrogen bond acceptor (HBA), molecular weight (MW), and lipophilicity (log P). PreADMET (https://preadmet.bmdrc.kr/) and pkCSM (http://biosig.unimelb.edu.au/pkcsm/) servers were employed to determine the ADMET (metabolism, distribution, excretion, absorption, and toxicity) attributes of target molecules.

\subsubsection{SwissADME (http://www.swissadme.ch/index.php)}

This website allows you to compute physicochemical descriptors as well as to predict ADME parameters, pharmacokinetic properties, druglike nature and medicinal chemistry friendliness of one or multiple small molecules to support drug discovery. This web service is a free web tool to evaluate pharmacokinetics, drug-likeness and medicinal chemistry friendliness of small molecules.[24] 
bioRxiv preprint doi: https://doi.org/10.1101/2021.07.18.452815; this version posted July 19, 2021. The copyright holder for this preprin (which was not certified by peer review) is the author/funder, who has granted bioRxiv a license to display the preprint in perpetuity. It is made available under aCC-BY-NC 4.0 International license.

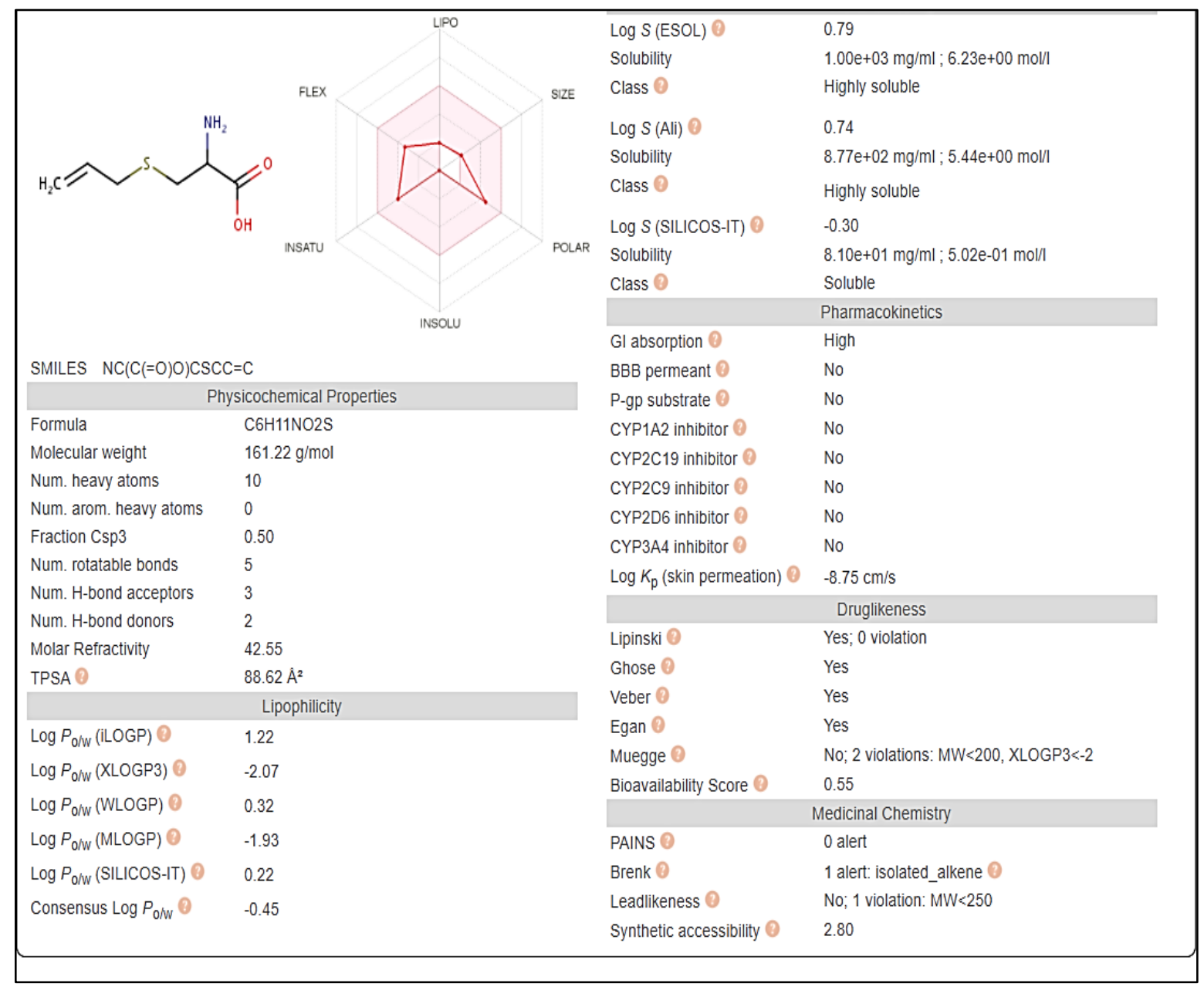

Fig 5 physicochemical descriptor, ADME parameters, pharmacokinetic properties, druglike nature and medicinal chemistry friendliness of Sallylcysteine ( SAC ) predicted by SwissADME Database SwissADME (http://www.swissadme.ch/index.php) 


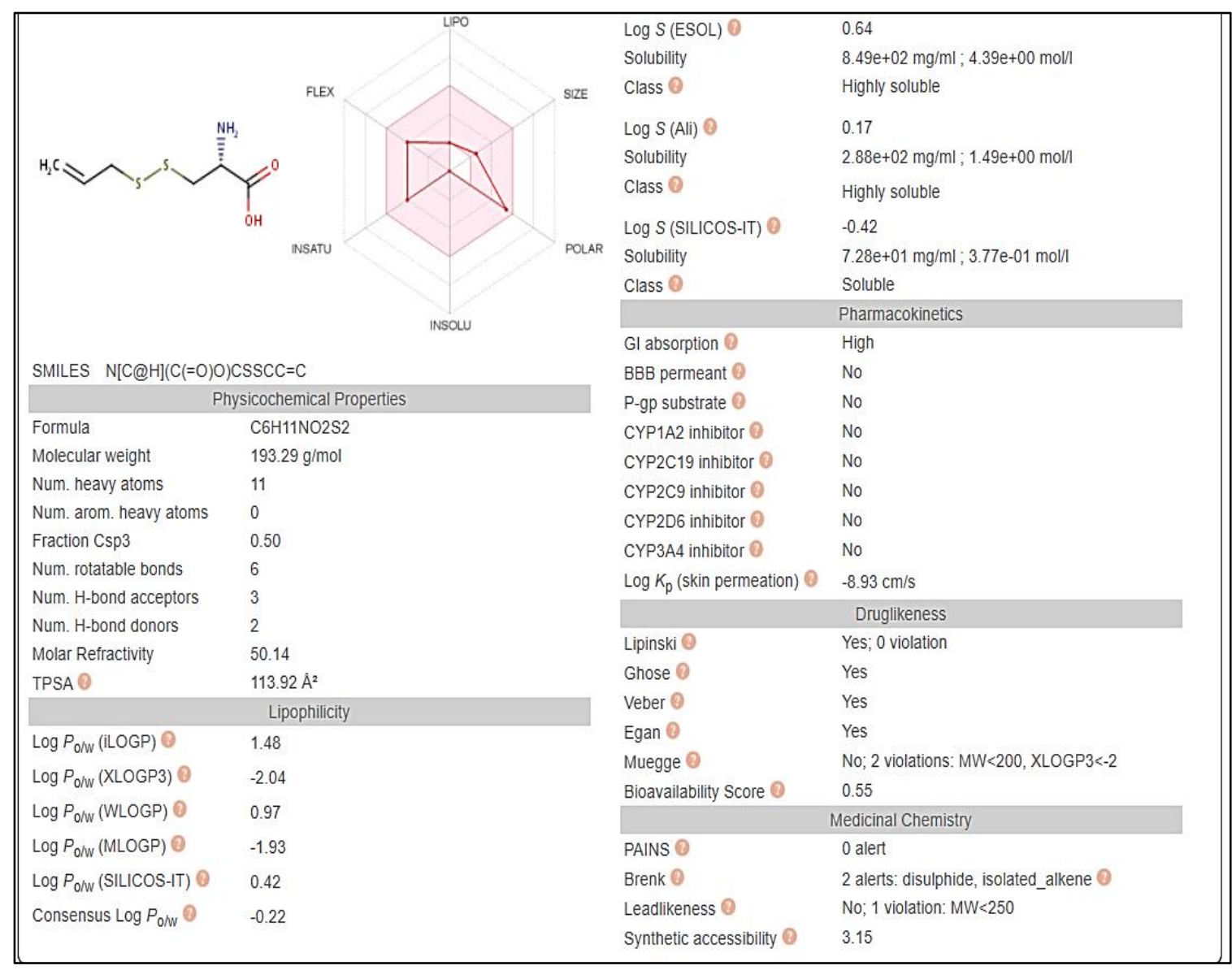

Fig 6 physicochemical descriptors), ADME parameters, pharmacokinetic properties, druglike nature and medicinal chemistry friendliness of Sallylmercaptocysteine (SAMC) predicted by SwissADME Database SwissADME (http://www.swissadme.ch/index.php)

\subsubsection{PreADMET (https://preadmet.bmdrc.kr/)}

PreADMET is a web-based application for predicting ADME data and building drug-like library using in silico method. It was describe a new web-based application called PreADMET, which has been developed in response to a need for rapid prediction of drug-likeness and ADME/Tox data. [2526] In figure 7 we report ADMET (metabolism, distribution, excretion, absorption, and toxicity) attributes of S-allylcysteine ( SAC ) ) predicted by PreADMET (https://preadmet.bmdrc.kr/ ):

- $\mathrm{BBB}$ (in vivo blood-brain barrier penetration (C.brain/C.blood) $>>0.229899$ Value

- Calculated water solubility value in buffer system by SK atomic types (mg/L) > 92985.4 Value

- in vitro Caco2 cell permeability (Human colorectal carcinoma; $\mathrm{nm} / \mathrm{sec}$ ) $>$ > 6.65342 Value

- in vitro Cytochrome P450 2C19 inhibition >> Inhibitor

- in vitro Cytochrome P450 2C9 inhibition >> Inhibitor

- in vitro Cytochrome P450 2D6 inhibition >> Inhibitor

- in vitro Cytochrome P450 2D6 substrate $>>$ No value

- in vitro Cytochrome P450 3A4 inhibition >> No value

- Human intestinal absorption (HIA, \%) >> 81.972219 Value

- in vitro MDCK cell permeability (Mandin Darby Canine Kidney) >> 209.694

- in vitro P-glecoprotein inhibition >> No value

- in vitro plasma protein binding $(\%) \gg 11.674627$

- in vitro skin permeability (transdermal delivery) $>>-3.10116$ Value 
bioRxiv preprint doi: https://doi org/101101/2021 07 18.452815; this version posted July 19, 2021. The copyright holder for this preprin (which was not certified by peer review) is the author/funder, who has granted bioRxiv a license to display the preprint in perpetuity. It is made available under aCC-BY-NC 4.0 International license.

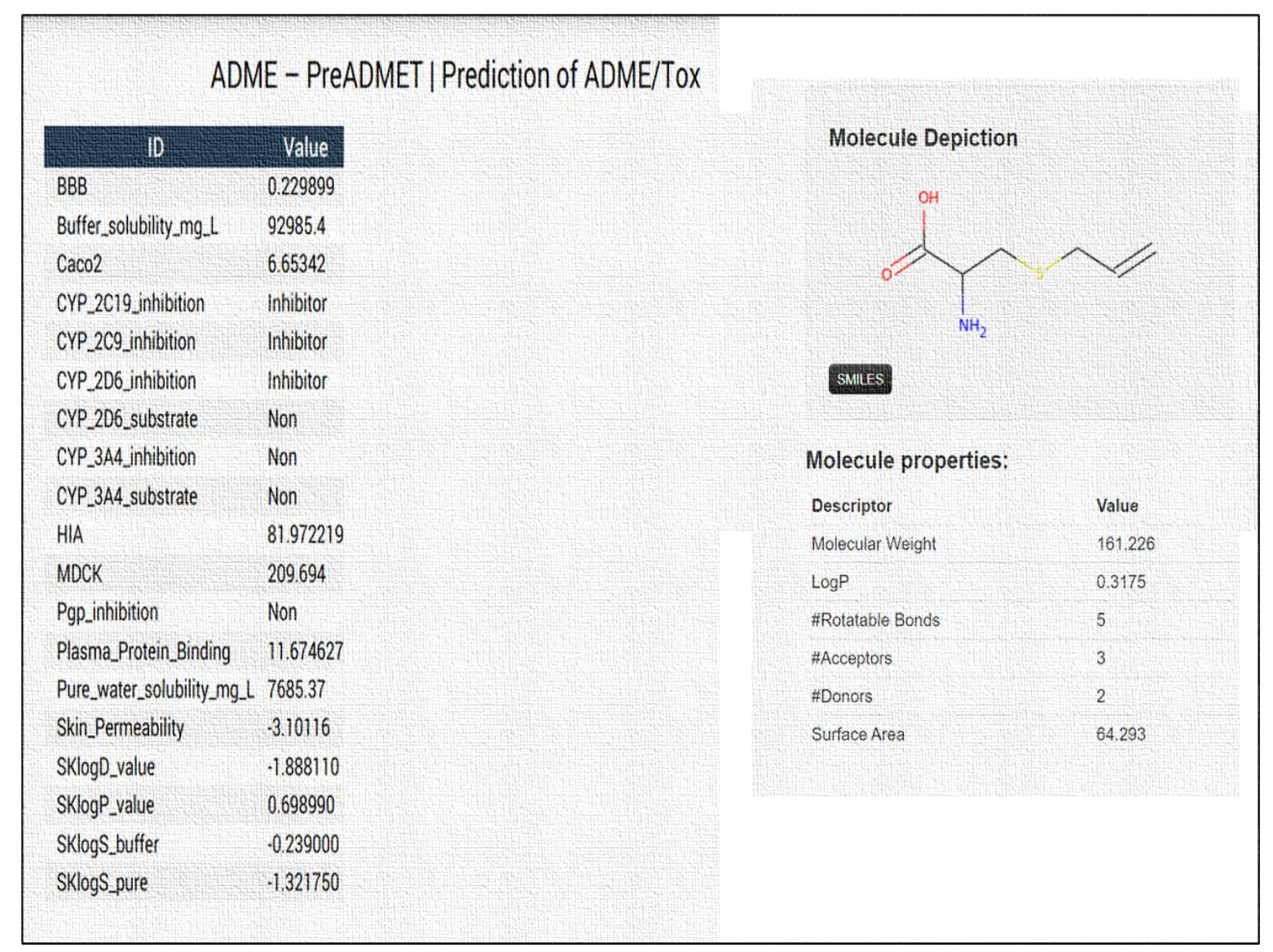

Fig 7 ADMET (metabolism, distribution, excretion, absorption, and toxicity) attributes of S-allylcysteine ( SAC) predicted by PreADMET (https://preadmet.bmdrc.kr/)

In figure 8 we report ADMET (metabolism, distribution, excretion, absorption, and toxicity) attributes of S-allylmercaptocysteine (SAMC) predicted by PreADMET (https://preadmet.bmdrc.kr/):

- BBB (in vivo blood-brain barrier penetration (C.brain/C.blood) $>0.190643$ Value

- Calculated water solubility value in buffer system by SK atomic types $(\mathrm{mg} / \mathrm{L})>>2537.48$ Value

- in vitro Caco2 cell permeability (Human colorectal carcinoma; nm/sec) >> 1.60099 Value

- in vitro Cytochrome P450 2C19 inhibition >> Inhibitor

- in vitro Cytochrome P450 2C9 inhibition >> Inhibitor

- in vitro Cytochrome P450 2D6 inhibition >> Weakly

- in vitro Cytochrome P450 2D6 substrate $>>$ No value

- in vitro Cytochrome P450 3A4 inhibition >> No value

- Human intestinal absorption (HIA, \%) >> 82.576618 Value

- in vitro MDCK cell permeability (Mandin Darby Canine Kidney) > 201.239

- in vitro P-glecoprotein inhibition $>>$ No value

- in vitro plasma protein binding $(\%)>0.000000$

- in vitro skin permeability (transdermal delivery) >> -2.8397 Value 


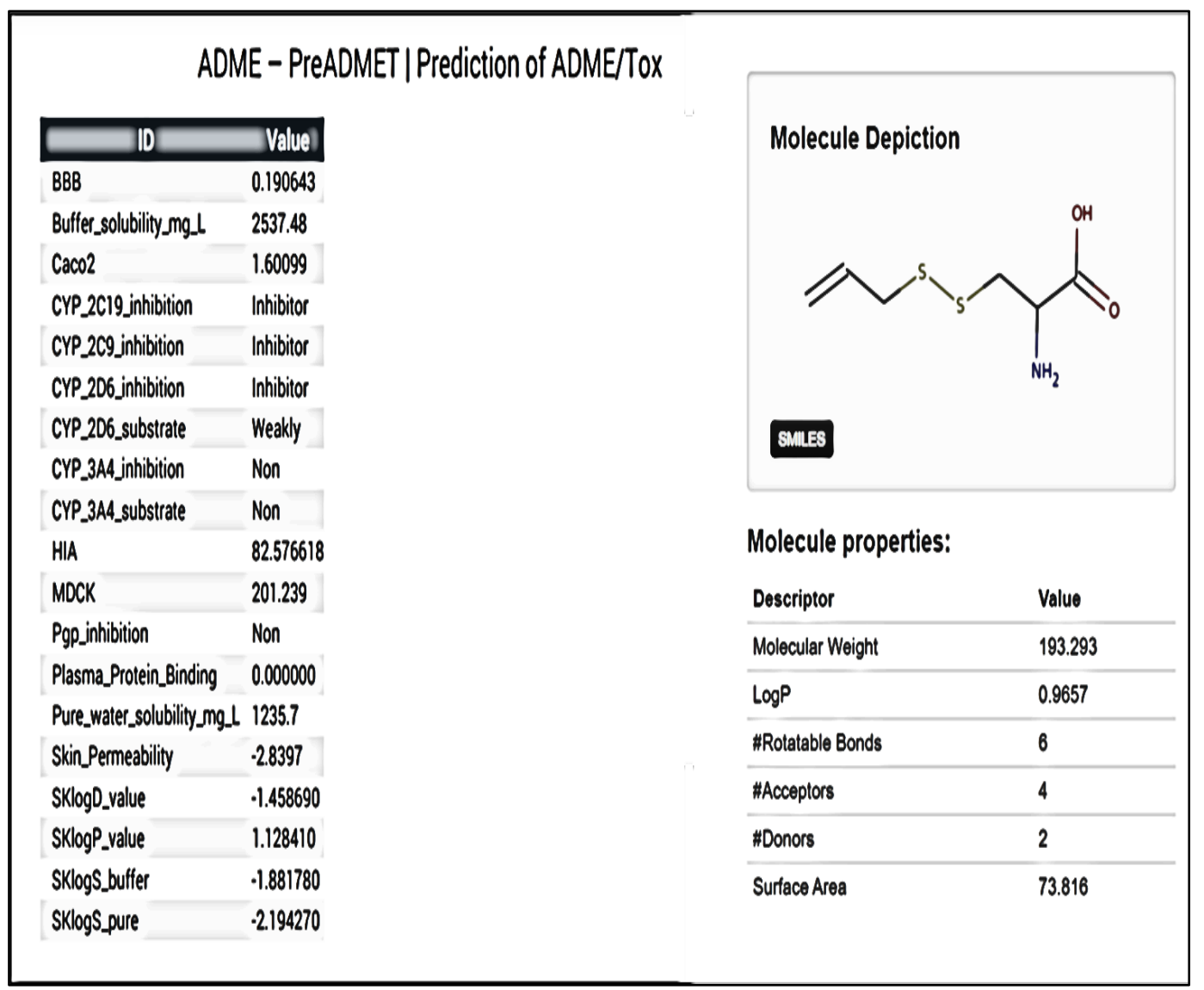

Fig 8 ADMET (metabolism, distribution, excretion, absorption, and toxicity) attributes of S-allylmercaptocysteine (SAMC) predicted by PreADMET (https://preadmet.bmdrc.kr/)[27]

\subsection{3 pkCSM (http://biosig.unimelb.edu.au/pkcsm/)}

Drug development has a high attrition rate, with poor pharmacokinetic and safety properties a significant hurdle. Computational approaches may help minimize these risks It was seen that pkCSM performs as well or better across different pharmacokinetic properties than other freely available methods. This server is useful for Small-molecule pharmacokinetics prediction. In figure 9- 10 we report Prediction of pharmacokinetic properties: ADMET (metabolism, distribution, excretion, absorption, and toxicity) attributes of S-allylcysteine ( SAC ) and S-allylcysteine ( SAMC) predicted by pkCSM, respectively. (http://biosig.unimelb.edu.au/pkcsm/ [27] 
bioRxiv preprint doi: https://doi.org/10.1101/2021.07.18.452815; this version posted July 19, 2021. The copyright holder for this preprin (which was not certified by peer review) is the author/funder, who has granted bioRxiv a license to display the preprint in perpetuity. It is made available under aCC-BY-NC 4.0 International license.

\begin{tabular}{|c|c|c|c|c|c|c|c|}
\hline Property & Model Name & Predicted Value & Unit & & & & \\
\hline Absoption & Water solubility & -2.888 & Numeric (log mollL) & & & & \\
\hline Absorption & Caco2 permeability & 0.704 & Numeric (log Papp in $10^{-6} \mathrm{~cm} / \mathrm{s}$ ) & Property & Model Name & Predicted Value & Unit \\
\hline Absorption & Intestinal absorption (human) & 79.971 & Numeric (\% Absorbed) & Excretion & Total Clearance & 0.591 & Numeric (log ml/min/kg) \\
\hline Absorption & Skin Permeability & -2.736 & Numeric $(\log K p)$ & Excretion & Renal OCT2 substrate & No & Categorical (Yes/No) \\
\hline Absorption & P-glycoprotein substrate & No & Categorical (Yes/No) & & & & \\
\hline Absorption & P-glycoprotein I inhibitor & No & Categorical (Yes/No) & & & & \\
\hline \multirow[t]{3}{*}{ Absorption } & P-glycoprotein || inhibitor & No & Categorical (Yes/No) & & & & \\
\hline & & & & Property & Model Name & Predicted Value & Unit \\
\hline & & & & Toxicity & AMES toxicity & No & Categorical (Yes/No) \\
\hline Metabolism & CYP2D6 substrate & No & Categorical (Yes/No) & Toxicity & hERG I inhibitor & No & Categorical (Yes/No) \\
\hline Metabolism & $\begin{array}{l}\text { CYPSA4 susstrate } \\
\text { CYP1A2 inhibitior }\end{array}$ & No & Categorical (Yes/No) & Toxicity & hERG II inhibitor & No & Categorical (Yes/No) \\
\hline Metabolism & CYP2C19 inhibitior & No & Categorical (Yes/No) & Toxicity & Oral Rat Acute Toxicity (LD50) & 2.02 & Numeric (mol/kg) \\
\hline Metabolism & CYP2C9 inhibitior & No & Categorical (Yes/No) & Toxicity & Oral Rat Chronic Toxicity (LOAEL) & 2.635 & Numeric (log mg/kg_bw/day) \\
\hline Metabolism & CYP2D6 inhibitior & No & Categorical (Yes/No) & Toxicity & Hepatotoxicity & No & Categorical (Yes/No) \\
\hline \multirow[t]{2}{*}{ Metabolism } & CYP3A4 inhibitior & No & Categorical (Yes/No) & Toxicity & Skin Sensitisation & No & Categorical (Yes/No) \\
\hline & & & & Toxicity & T.Pyniformis toxicity & 0.166 & Numeric (log ug/L) \\
\hline Property & Model Name & Predicted Value & Unit & Toxicity & Minnow toxicity & 2.088 & Numeric (log mM) \\
\hline Distribution & VDss (human) & -0.561 & Numeric (log Lkg) & & & & \\
\hline Distribution & Fraction unbound (human) & 0.444 & Numeric (Fu) & & & & \\
\hline Distribution & CNS permeability & -3.417 & Numeric (log PS) & & & & \\
\hline
\end{tabular}

Fig 9 Prediction of pharmacokinetic properties: ADMET (metabolism, distribution, excretion, absorption, and toxicity) attributes of S-allylcysteine ( SAC) SAMC) predicted by pkCSM (http://biosig.unimelb.edu.au/pkcsm/) [27] 


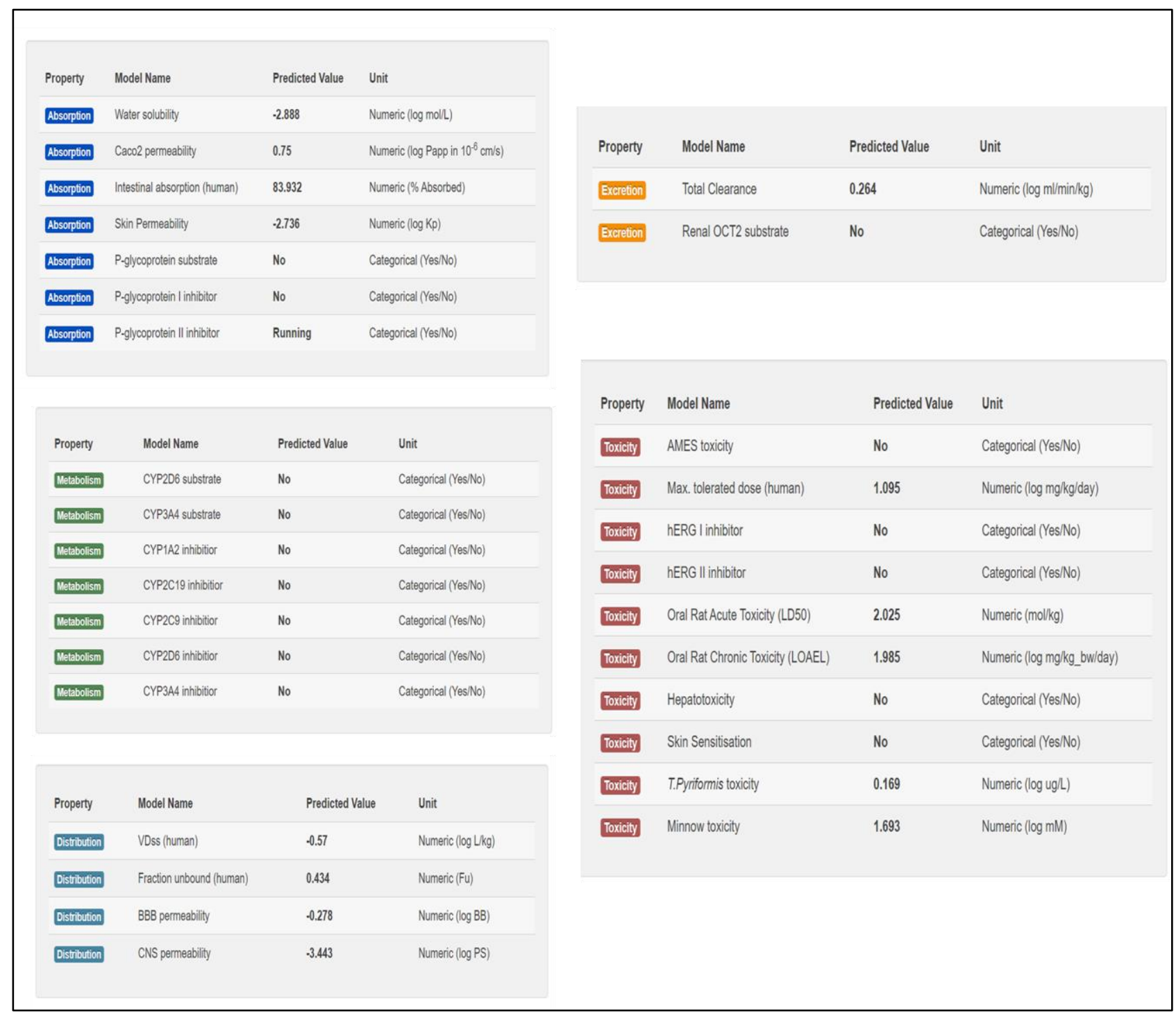

Fig 9 Prediction of pharmacokinetic properties: ADMET (metabolism, distribution, excretion, absorption, and toxicity) attributes of S-allylcysteine ( SAMC) predicted by pkCSM (http://biosig.unimelb.edu.au/pkcsm/)[27]

\section{Conclusions}

This paper encompasses the fundamental functions of open access in silico prediction tools, as PASS database (Prediction of Activity Spectra for Substances) that it estimates the probable biological activity profiles for compounds. This paper also aims to help support new researchers in the field of drug design and to investigate some of bioactive compounds in garlic. Particular attention we investigated Pharmacokinetic properties by several server, of S-allylcysteine ( SAC) and Sallylmercaptocysteine (SAMC) for their as anti-inflammatory, antibacterial, and antiviral, antioxidant, cardiovascular protective and anticancer property. Screening through each of pharmacokinetic criteria resulted in identification of Garlic compounds that adhere to all the ADMET properties. It was established an open-access database (PASS database, available bioinformatics tool SwissADME, PreADMET pkCSM database) servers were employed to determine the ADMET (metabolism, distribution, excretion, absorption, and toxicity) attributes of garlic molecules and to enable identification of promising molecules that follow ADMET properties. Further investigations will be conducted in Vitro and In vito by the SAMC, using Layered double hydroxides (LDH), which are one type of layered materials and are also known as anionic clays, are promising layered materials due to some of their interesting properties, such as to facile tunability of their composition, structure morphology and biocompatibility vehicle, against several cancer cells. 
bioRxiv preprint doi: https://doi org/10.1101/2021.07.18.452815; this version posted July 19,2021 . The copyright holder for this preprint (which was not certified by peer review) is the author/funder, who has granted bioRxiv a license to display the preprint in perpetuity. It is made available under aCC-BY-NC 4.0 International license.

\section{Author contributions}

I.V.F. conceived, designed and wrote the paper and performed the calculations and analyzed the data.

Declaration of Competing Interest

The authors declare they have no potential conflicts of interest to disclose.

\section{REFERENCES}

1. Shang, Ao., Cao , Shi-Yu., Xu , Xiao-Yu., Gan , Ren-You., Tang, Guo-Yi., Corke „H., Mavumengwana, V. and Li ,Hua-Bin. "Bioactive Compounds and Biological Functions of Garlic (Allium sativum L.) ( 2019) Foods, 8, 246; doi:10.3390/foods8070246

2. Zhang, Y., Xingping, Liu Ruan, J., Zhuang, X., Zhang, X. and Li, Z. "Phytochemicals of garlic: Promising candidates for cancer therapy". Biomedicin \& ( 2020) Pharmacotherapy 123, 109730

3. Zhou, Yong, et al. "Consumption of large amounts of Allium vegetables reduces risk for gastric cancer in a meta-analysis." Gastroenterology 141.1 (2011): 80-89.

4. Kodali, R. T., and Guy D. Eslick. "Meta-analysis: Does garlic intake reduce risk of gastric cancer?." Nutrition and cancer 67.1 (2015): 1-11.

5. Turati, Federica, et al. "Colorectal cancer and adenomatous polyps in relation to allium vegetables intake: A meta-analysis of observational studies." Molecular nutrition \& food research 58.9 (2014): 1907-1914.

6. Lipinski, Christopher A. "Lead-and drug-like compounds: the rule-of-five revolution." Drug Discovery Today: Technologies 1.4 (2004): 337-341.

7. Daina, Antoine, Olivier Michielin, and Vincent Zoete. "SwissADME: a free web tool to evaluate pharmacokinetics, drug-likeness and medicinal chemistry friendliness of small molecules." Scientific reports 7.1 (2017): 1-13.

8. Alexey Lagunin, Alla Stepanchikova, Dmitrii Filimonov, Vladimir Poroikov, PASS: prediction of activity spectra for biologically active substances , Bioinformatics, Volume 16, Issue 8, August 2000, Pages 747-748, https://doi.org/10.1093/bioinformatics/16.8.747

9. http://www.pharmaexpert.ru/PASSOnline/info.php

10. Shirin, Haim., Pinto, J. T. Kawabata, Y. Soh, Delohery, Jae-Won T. Moss, S.F. Vundavalli Murty, Richard S. Rivlin, Peter R. Holt and I. Bernard Weinstein "Antiproliferative Effects of S-Allylmercaptocysteine on Colon Cancer Cells When Tested Alone or in Combination with Sulindac Sulfide". CANCER RESEARCH 61 pp.725-731

11. Lokman Uzun, Numan Kokten, Osman Halit Cam, M.Tayyar Kalcioglu, M. Birol Ugur, Muhammet Tekin, Gul Ozbilen Acar. "The effect of Garlic Derivatives (SAllylmercaptocysteine, Diallyl Disulfide, and S-Allylcysteine) on Gentamicin Induced Ototoxicity: An Experimental Study" (2016) Clinical and Experimental Otorhinolaryngology 9,(4) pp.309-313

12. LV, Yi., SO, Kwok-Fai, WONG, Nai-Kei, and XIAO, Jia, "Anti-cancer activities of Sallylmercaptocysteine from aged garlic". (2019) Chinese Journal of Natural Medicines, 17 (1) pp.43-49 
13. Shirin, Haim., Pinto, J. T. Kawabata, Y. Soh, Delohery, Jae-Won T. Moss, S.F. Vundavalli Murty, Richard S. Rivlin, Peter R. Holt and I. Bernard Weinstein "Antiproliferative Effects of S-Allylmercaptocysteine on Colon Cancer Cells When Tested Alone or in Combination with Sulindac Sulfide". (2001) CANCER RESEARCH 61 pp.725-731

14. Dandan Tong, Hui Qu Xiangning Meng Yang Jiang Duanyang Liu Shengqian Ye He Chen Yan Jin Songbin Fu Jingshu Geng. S-allylmercaptocysteine promotes MAPK inhibitorinduced apoptosis by activating the TGF- $\beta$ signaling pathway in cancer cells. ( 2014) Oncology reports,32 (3)pp. 1124-1132

15. J.-Y. Yan, F.-M. Tian, W.-N. Hu, J.-H. Zhang, H.-F. Cai, N. Li "Apoptosis of human gastric cancer cells line SGC 7901 induced by garlic-derived compound S-allylmercaptocysteine (SAMC)" (2013) Eur Rev Med Pharmacol Sci ,17 (6) pp.745-751

16. Xiaosong Zhua, Xiaoyan Jiang, Chonggang Duan, Ang Li, Yueyue Suna, Qiuchen Qi, Yan Liu, Siying Li, and Zhongxi Zhao." S-Allylmercaptocysteine induces G2/M phase arrest and apoptosis via ROS-mediated p38 and JNK signaling pathway in human colon cancer cells in vitro and in vivo".(2017) SC Adv., 7, pp.49151-49158

17. Qingjun, Chu." S-Allylcysteine (Sac) and S-Allylmercaptocysteine (Samc), Water Soluble Garlic Derivatives, Suppress Growth and Invasion of Androgen-Independent Prostate Cancer, Under in Vitro and in Vivo Conditions". (2017) 褚慶軍

Liu, Y., Yan, J., Han, X. and Hu, W.” Garlic-derived compound S-allylmercaptocysteine (SAMC) is active against anaplastic thyroid cancer cell line 8305C (HPACC)".(2015) Technol Health Care. 23, (1) pp. S89-S93

18. Pinto, J. T. and Rivlin," R., S. Antiproliferative Effects of Allium Derivatives from Garlic". ( 2001) The Journal of Nutrition, 131 (3) pp. 1058S-1060S

19. Pinto, J. T., Qiao, C. H., Xing, J., Brian, P., Suffoletto, B. P., Schubert, K. B., Rivlin, R. S., Huryk, R. F., Bacich, D. J. \& Heston, W. D. W. (2000)" Alterations of prostate biomarker expression and testosterone utilization in human $\mathrm{LNCaP}$ prostatic carcinoma cells by garlicderived S-allylmercaptocysteine". The Prostate, 45 pp.304-314.

20. Xiao D, Pinto JT, Soh JW, Deguchi A, Gundersen GG, Palazzo AF, Yoon JT, Shirin H, Weinstein IB". Induction of apoptosis by the garlic-derived compound Sallylmercaptocysteine (SAMC) is associated with microtubule depolymerization and c-Jun NH(2)-terminal kinase 1 activation". (2003) Cancer Res. 63(20) pp.6825-37.

21. Biovia, Dassault Systèmes. "Discovery studio modeling environment." (2017).

22. Filimonov, Dmitry, and Vladimir Poroikov. Probabilistic approaches in activity prediction. Royal Society of Chemistry, Cambridge, UK, 2008.

23. Lagunin, Alexey, et al. "PASS: prediction of activity spectra for biologically active substances." Bioinformatics 16.8 (2000): 747-748.

24. Daina A, Michielin O, Zoete V. SwissADME: a free web tool to evaluate pharmacokinetics, drug-likeness and medicinal chemistry friendliness of small molecules. Scientific Reports. 2017 Mar; 7:42717. DOI: 10.1038/srep42717.

25. S.K.Lee, G.S.Chang, I.H.Lee, J.E.Chung, K.Y.Sung, K.T.No, “The PreADME: PC-BASED PROGRAM FOR BATCH PREDICTION OF ADME PROPERTIES“, EuroQSAR 2004, 2004, 9.5-10, Istanbul, Turkey.

26. S.K.Lee, I.H.Lee,H.J.Kim, G.S.Chang, J.E.Chung, K.T.No, “The PreADME Approach: Web-based program for rapid prediction of physico-chemical, drug absorption and drug-like 
properties“, EuroQSAR 2002 Designing Drugs and Crop Protectants: processes, problems and solutions, 2003, pp. 418-420. Blackwell Publishing, Massachusetts, USA.

27. Pires, Douglas EV, Tom L. Blundell, and David B. Ascher. "pkCSM: predicting smallmolecule pharmacokinetic and toxicity properties using graph-based signatures." Journal of medicinal chemistry 58.9 (2015): 4066-4072.

28. Phillips IR, Shephard EA. Flavin-containing monooxygenase 3 (FMO3): genetic variants and their consequences for drug metabolism and disease. Xenobiotica. 2020 Jan;50(1):19-33. doi: 10.1080/00498254.2019.1643515. Epub 2019 Aug 1. PMID: 31317802.

29. Valentino, Hannah, et al. "Structure and function of a flavin-dependent S-monooxygenase from garlic (Allium sativum)." Journal of Biological Chemistry 295.32 (2020): 11042-11055.

30. Ferreira F, Esteves S, Almeida LS, Gaspar A, da Costa CD, Janeiro P, Bandeira A, Martins E, Teles EL, Garcia P, Azevedo L, Vilarinho L. Trimethylaminuria (fish odor syndrome): genotype characterization among Portuguese patients. Gene. 2013 Sep 15;527(1):366-70. doi: 10.1016/j.gene.2013.05.025. Epub 2013 Jun 17. PMID: 23791655. 
bioRxiv preprint doi: https://doi.org/10.1101/2021.07.18.452815; this version posted July 19, 2021. The copyright holder for this preprint (which was not certified by peer review) is the author/funder, who has granted bioRxiv a license to display the preprint in perpetuity. It is made available under aCC-BY-NC 4.0 International license.

\begin{tabular}{|c|c|c|c|c|c|}
\hline Compound & Molecular Formula & Molecular Weight $(\mathrm{g} / \mathrm{mol})$ & $\mathrm{Pa}$ & $\mathrm{Pi}$ & Acitivity \\
\hline \multirow{6}{*}{ (E)-Ajoene and Z)-Ajoene } & $\mathrm{C}_{9} \mathrm{H}_{14} \mathrm{OS}_{3}$ & 234.4 & 0,972 & 0,004 & Antineoplastic \\
\hline & & & 0,949 & 0,002 & CYP2E1 inhibitor \\
\hline & & & 0,94 & 0,004 & Apoptosis agonist \\
\hline & & & 0,881 & 0,004 & CYP2E1 substrate \\
\hline & & & 0,875 & 0,004 & CYP2E substrate \\
\hline & & & 0,869 & 0,001 & Chemoprotective \\
\hline \multirow[t]{9}{*}{ Vinylthiiran } & $\mathrm{C}_{4} \mathrm{H}_{6} \mathrm{~S}$ & 86.16 & $\mathrm{~Pa}$ & $\mathrm{Pi}$ & Acitivity \\
\hline & & & 0,932 & 0,001 & Growth hormone agonist \\
\hline & & & 0,926 & 0,003 & Gluconate 2-dehydrogenase (acceptor) inhibitor \\
\hline & & & 0,865 & 0,003 & Chloride peroxidase inhibitor \\
\hline & & & 0,875 & 0,014 & Aspulvinone dimethylallyltransferase inhibitor \\
\hline & & & 0,822 & 0,013 & Mucomembranous protector \\
\hline & & & 0,81 & 0,004 & Fatty-acyl-CoA synthase inhibitor \\
\hline & & & 0,806 & 0,004 & Thioredoxin inhibitor \\
\hline & & & 0,802 & 0,006 & Cl--transporting ATPase inhibitor \\
\hline \multirow{4}{*}{ Allicin } & $\mathrm{C}_{6} \mathrm{H}_{10} \mathrm{OS} S_{2}$ & 162.3 & $\mathrm{~Pa}$ & $\mathrm{Pi}$ & Acitivity \\
\hline & Cotinos & & 0,959 & 0,003 & Apoptosis agonist \\
\hline & & & 0,884 & 0,001 & Chemoprotective \\
\hline & & & 0,852 & 0,02 & Aspulvinone dimethylallyltransferase inhibitor \\
\hline \multirow[t]{8}{*}{ gamma-Glutamylcysteine } & $\mathrm{C}_{8} \mathrm{H}_{14} \mathrm{~N}_{2} \mathrm{O}_{5} \mathrm{~S}$ & 250.27 & $\mathrm{~Pa}$ & $\mathrm{Pi}$ & Acitivity \\
\hline & 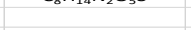 & & 0,984 & 0,001 & Mucositis treatment \\
\hline & & & 0,983 & 0,001 & Protein-disulfide reductase (glutathione) inhibitor \\
\hline & & & 0,982 & 0 & Hydrogen dehydrogenase inhibitor \\
\hline & & & 0,979 & 0 & Yeast ribonuclease inhibitor \\
\hline & & & 0,976 & 0,001 & Fucosterol-epoxide lyase inhibitor \\
\hline & & & 0,974 & 0,001 & Levanase inhibitor \\
\hline & & & 0,97 & 0,002 & Monodehydroascorbate reductase (NADH) inhibito \\
\hline \multirow[t]{10}{*}{ S-Allyl-L-cysteine } & $\mathrm{C}_{6} \mathrm{H}_{11} \mathrm{NO}_{2} \mathrm{~S}$ & 161.22 & $\mathrm{~Pa}$ & $\mathrm{Pi}$ & Acitivity \\
\hline & & & 0,965 & 0,002 & Flavin-containing monooxygenase substrate \\
\hline & & & 0,963 & 0,003 & CYP2E1 substrate \\
\hline & & & 0,962 & 0,003 & $\begin{array}{l}\text { CYP2E substrate } \\
\text { CYlate }\end{array}$ \\
\hline & & & 0,942 & 0,001 & S-alkylcysteine lyase inhibitor \\
\hline & & & 0,939 & 0,002 & NADPH peroxidase inhibitor \\
\hline & & & 0,933 & 0,002 & FMO3 substrate \\
\hline & & & 0,928 & 0,002 & Lysine 2,3-aminomutase inhibitor \\
\hline & & & 0,924 & 0,003 & Acylcarnitine hydrolase inhibitor \\
\hline & & & 0,905 & 0,004 & Arylacetonitrilase inhibitor \\
\hline S-allylmercapto-L-cysteine & $\mathrm{C}_{6} \mathrm{H}_{11} \mathrm{NO}_{2} \mathrm{~S}_{2}$ & 193.3 & $\mathrm{~Pa}$ & $\mathrm{Pi}$ & Acitivity \\
\hline & & & 0,974 & 0,002 & Flavin-containing monooxygenase substrate \\
\hline & & & 0,967 & 0,001 & FMO3 substrate \\
\hline & & & 0,939 & 0,002 & NADPH peroxidase inhibitor \\
\hline & & & 0,939 & 0,002 & Protein-disulfide reductase (glutathione) inhibitor \\
\hline & & & 0,934 & 0,003 & CYP2E1 substrate \\
\hline & & & 0,933 & 0,003 & CYP2E substrate \\
\hline & & & 0,932 & 0,003 & Antiseborrheic \\
\hline & & & 0,928 & 0,003 & Lipid metabolism regulator \\
\hline & & & 0,925 & 0,004 & Apoptosis agonist \\
\hline & & & 0,924 & 0,003 & Acylcarnitine hydrolase inhibitor \\
\hline & & & 0,919 & 0,001 & Cysteamine dioxygenase inhibitor \\
\hline & & & 0,916 & 0,003 & Arylacetonitrilase inhibitor \\
\hline & & & 0,909 & 0,002 & S-alkylcysteine lyase inhibitor \\
\hline & & & 0,903 & 0,005 & TP53 expression enhancer \\
\hline Allyl methyl sulfide & $\mathrm{C}_{4} \mathrm{H}_{8} \mathrm{~S}$ & 88.17 & $\mathrm{~Pa}$ & $\mathrm{Pi}$ & Acitivity \\
\hline & & & 0,965 & 0,002 & Flavin-containing monooxygenase substrate \\
\hline & & & 0,941 & 0,004 & Apoptosis agonist \\
\hline & & & 0,935 & 0,002 & FMO3 substrate \\
\hline & & & 0,914 & 0,004 & Mucomembranous protector \\
\hline & & & 0,9 & 0,003 & CYP2E1 inhibitor \\
\hline & & & 0,876 & 0,002 & S-alkylcysteine lyase inhibitor \\
\hline Diallyl sulfide & $\mathrm{C}_{6} \mathrm{H}_{10} \mathrm{~S}$ & 114.21 & $\mathrm{~Pa}$ & $\mathrm{Pi}$ & Acitivity \\
\hline & & & 0,926 & 0,002 & Flavin-containing monooxygenase substrate \\
\hline & & & 0,889 & 0,01 & Aspulvinone dimethylallyltransferase inhibitor \\
\hline & & & 0,876 & 0,006 & Mucomembranous protector \\
\hline & & & 0,872 & 0,002 & FMO3 substrate \\
\hline & & & 0,869 & 0,003 & Fatty-acyl-CoA synthase inhibitor \\
\hline Diallyl disulfide & $\mathrm{C}_{6} \mathrm{H}_{10} \mathrm{~S}_{2}$ & 146.3 & $\mathrm{~Pa}$ & $\mathrm{Pi}$ & Acitivity \\
\hline & & & 0,987 & 0,002 & Apoptosis agonist \\
\hline & & & 0,944 & 0,001 & Cysteamine dioxygenase inhibitor \\
\hline & & & 0,935 & 0,003 & CYP2E1 inhibitor \\
\hline & & & 0,931 & 0,003 & Inflammatory Bowel disease treatment \\
\hline & & & 0,92 & 0,001 & $\mathrm{Bcl} 2$ antagonist \\
\hline & & & 0,917 & 0,001 & Chemoprotective \\
\hline & & & 0,904 & 0,003 & Antioxidant \\
\hline & & & 0,896 & 0,003 & Atherosclerosis treatment \\
\hline Diallyl trisulfide & $\mathrm{C}_{6} \mathrm{H}_{1053}$ & 178.3 & $\mathrm{~Pa}$ & $\mathrm{Pi}$ & Acitivity \\
\hline & & & 0,981 & 0,001 & Antineoplastic (cervical cancer) \\
\hline & & & 0,979 & 0,002 & Antineoplastic (ovarian cancer) \\
\hline & & & 0,977 & 0,004 & Antineoplastic \\
\hline & & & 0,97 & 0,002 & Antineoplastic (lymphocytic leukemia) \\
\hline & & & 0,964 & 0 & Antineoplastic (sarcoma) \\
\hline & & & 0,955 & 0,003 & Apoptosis agonist \\
\hline & & & 0,94 & 0,002 & Antineoplastic (non-small cell lung cancer) \\
\hline
\end{tabular}

Tab 2 PASS Online Server (Prediction of Activity Spectra for Substances) of Principal Organosulfur Compounds in Garlic. The output file represents a list of activities with two probabilities Pa (probability to be active) and Pi (probability to be inactive). Pa (probability "to be active") estimates the chance that the studied compound is belonging to the sub-class of active compounds (resembles the structures of molecules, which are the most typical in a sub-set of "actives" in PASS training set). Pi (probability "to be inactive") estimates the chance that the studied compound is belonging to the sub-class of inactive compounds (resembles the structures of molecules, which are the most typical in a sub-set of "inactives" in PASS training set). [8] 
bioRxiv preprint doi: https://doi.org/10.1101/2021.07.18.452815; this version posted July 19, 2021. The copyright holder for this preprint (which was not certified by peer review) is the author/funder, who has granted bioRxiv a license to display the preprint in perpetuity. It is made available under aCC-BY-NC 4.0 International license.

\begin{tabular}{|c|c|c|c|c|c|}
\hline \multirow{5}{*}{$\begin{array}{c}\text { Compound } \\
\text { (E)-Ajoene and Z)-Ajoene }\end{array}$} & \multicolumn{2}{|c|}{ Molecular Formula Volecular Weight $(\mathrm{g} / \mathrm{mol}$} & \multirow{2}{*}{$\begin{array}{c}\mathrm{Pa} \\
0,449\end{array}$} & \multirow{2}{*}{$\begin{array}{c}\mathrm{Pi} \\
0,036\end{array}$} & \multirow{2}{*}{$\begin{array}{l}\text { Possible adverse \& toxic effects } \\
\text { Thrombocytopoiesis inhibitor }\end{array}$} \\
\hline & $\mathrm{C}_{9} \mathrm{H}_{14} \mathrm{OS}_{3}$ & 234.4 & & & \\
\hline & & & 0,371 & 0,093 & Adrenal cortex hypoplasia \\
\hline & & & 0,36 & 0,103 & Weight gain \\
\hline & & & 0,311 & 0,123 & Hypomagnesemia \\
\hline & & & & & \\
\hline \multirow[t]{8}{*}{ Vinylthiiran } & $\mathrm{C}_{4} \mathrm{H}_{5} \mathrm{~S}$ & 86.16 & $\mathrm{~Pa}$ & $\mathrm{Pi}$ & Possible adverse \& toxic effects \\
\hline & & & 0,907 & 0,005 & Weight loss \\
\hline & & & 0,801 & 0,019 & Weakness \\
\hline & & & 0,771 & 0,017 & Nephrotoxic \\
\hline & & & 0,765 & 0,017 & Muscle weakness \\
\hline & & & & & \\
\hline & & & & & \\
\hline & & & & & \\
\hline \multirow[t]{4}{*}{ Allicin } & $\mathrm{C}_{6} \mathrm{H}_{10} \mathrm{OS}_{2}$ & 162.3 & $\mathrm{~Pa}$ & $\mathrm{Pi}$ & Possible adverse \& toxic effects \\
\hline & & & 0,682 & 0,011 & Thrombocytopoiesis inhibitor \\
\hline & & & 0,616 & 0,046 & Withdrawal \\
\hline & & & 0,639 & 0,073 & ophilic dermatosis (Sweet's syndrome) \\
\hline \multirow{8}{*}{ gamma-Glutamylcysteine } & $\mathrm{C}_{9} \mathrm{H}_{1} \mathrm{~N}_{2} \mathrm{O}_{5} \mathrm{~S}$ & 250.27 & $\mathrm{~Pa}$ & $\mathrm{Pi}$ & Possible adverse $\&$ toxic effects \\
\hline & & & 0,924 & 0,001 & Bullous pemphigoid \\
\hline & & & 0,891 & 0,008 & Pure red cell aplasia \\
\hline & & & 0,858 & 0,007 & Ulcer, aphthous \\
\hline & & & 0,852 & 0,003 & Anemia, sideroblastic \\
\hline & & & 0,856 & 0,011 & Neurotoxic \\
\hline & & & 0,857 & 0,016 & Diarrhea \\
\hline & & & 0,809 & 0,012 & Nephrotoxic \\
\hline \multirow{9}{*}{ S-Allyl-L-cysteine } & $\mathrm{C}_{\mathrm{H}} \mathrm{H}_{1} \mathrm{NO}_{2} \mathrm{~S}$ & 161,22 & $\mathrm{~Pa}$ & $\mathrm{Pi}$ & Possibbe adverse \& toxic effects \\
\hline & $\mathrm{C}_{6} \mathrm{n}_{11} \mathrm{NU}_{2} \mathrm{~S}$ & & 0,835 & 0,017 & Pure red cell aplasia \\
\hline & & & 0,832 & 0,02 & Diarrhea \\
\hline & & & 0,801 & 0,017 & Neurotoxic \\
\hline & & & 0,786 & 0,004 & Anemia, sideroblastic \\
\hline & & & 0,784 & 0,022 & Ulcer, aphthous \\
\hline & & & & & \\
\hline & & & & & \\
\hline & & & & & \\
\hline S-allylmercapto-L-cysteine & $\mathrm{C}_{6} \mathrm{H}_{11} \mathrm{NO}_{2} \mathrm{~S}_{2}$ & 193.3 & $\mathrm{~Pa}$ & $\mathrm{Pi}$ & Possible adverse \& toxic effects \\
\hline & & & 0,786 & 0,004 & Anemia, sideroblastic \\
\hline & & & 0,804 & 0,023 & Pure red cell aplasia \\
\hline & & & 0,783 & 0,015 & Nephrotoxic \\
\hline & & & 0,777 & 0,02 & Neurotoxic \\
\hline & & & 0,764 & 0,014 & Ataxia \\
\hline & & & 0,758 & 0,028 & Ulcer, aphthous \\
\hline & & & 0,716 & 0,021 & Weight gain \\
\hline & & & 0,728 & 0,039 & Toxic \\
\hline & & & & & \\
\hline & & & & & \\
\hline & & & & & \\
\hline & & & & & \\
\hline & & & & & \\
\hline Allyl methyl sulfide & $\mathrm{C}_{4} \mathrm{H}_{8} \mathrm{~S}$ & 88.17 & $\mathrm{~Pa}$ & $\mathrm{Pi}$ & Possible adverse \& toxic effects \\
\hline & & & 0,819 & 0,006 & Thrombocytopoiesis inhibitor \\
\hline & & & 0,725 & 0,012 & Hypothermic \\
\hline & & & 0,708 & 0,005 & Lacrimal secretion stimulant \\
\hline & & & 0,711 & 0,027 & Hyperglycemic \\
\hline & & & & & \\
\hline & & & & & \\
\hline Diallyl sulfide & $\mathrm{C}_{6} \mathrm{H}_{10} \mathrm{~S}$ & 114.21 & $\mathrm{~Pa}$ & $\mathrm{Pi}$ & Possible adverse $\&$ toxic effects \\
\hline & & & 0,801 & 0,006 & Thrombocytopoiesis inhibitor \\
\hline & & & 0,769 & 0,008 & Withdrawal \\
\hline & & & 0,77 & 0,011 & Weight gain \\
\hline & & & 0,781 & 0,028 & ophilic dermatosis (Sweet's syndrome) \\
\hline & & & 0,795 & 0,044 & Twitching \\
\hline Diallyl disulfide & $\mathrm{C}_{\mathrm{CH}} \mathrm{S}_{3}$ & 1463 & $\mathrm{~Pa}$ & $\mathrm{Pi}$ & Possible adverse \& toxic effects \\
\hline & & & 0,888 & 0,004 & Thrombocytopoiesis inhibitor \\
\hline & & & 0,787 & 0,043 & Shivering \\
\hline & & & 0,741 & 0,011 & Withdrawal \\
\hline & & & 0,734 & 0,017 & Weight gain \\
\hline & & & 0,719 & 0,02 & Ataxia \\
\hline & & & 0,738 & 0,04 & ophilic dermatosis (Sweet's syndrome) \\
\hline & & & 0,705 & 0,016 & Hypomagnesemia \\
\hline & & & 0,755 & 0,067 & Twitching \\
\hline Diallyl trisulfide & $\mathrm{C}_{6} \mathrm{H}_{1053}$ & 178.3 & $\mathrm{~Pa}$ & $\mathrm{Pi}$ & Possible adverse \& toxic effects \\
\hline & & & 0,734 & 0,009 & Thrombocytopoiesis inhibitor \\
\hline & & & 0,711 & 0,073 & Shivering \\
\hline
\end{tabular}

Tab 3 PASS Online Server (Prediction of Activity Spectra for Substances) calculated possible adverse and toxic effects of Principal Organosulfur Compounds in Garlic [8] 